\title{
Spirituality in a group of elderly Mexican residents of old people's Home: a brief descriptive report
}

\author{
Abstract \\ Objective: To describe spirituality in a group of elderly Mexican residents of old \\ people's home.
}

Methods: Quantitative, observational, descriptive and cross-sectional study, conducted from July 2017 to January 2018, consecutive non-probabilistic sampling $(n=28)$ in 7 old people's home in Mexico. Information collected through the Spiritual Perspective Scale (SPS), descriptive analysis.

Results: Spirituality through the Spiritual Perspective Scale averaged 46.50 (+/- 9.09), considered high in the group of elderly residents. Studies with elderly caregivers and chronic illnesses reveal that spirituality is favored in old age. Studies suggest that spirituality is a resource that generates well-being in old age.

Conclusion: The elderly is spiritual, in old age there is a high spiritual sense, and spirituality is a phenomenon of interest for nursing from the holistic view of the human being that fosters a vision of spiritual care until intervention with institutionalized elders.

Keywords: spirituality, nursing, old people's home, spiritual care
Volume 5 Issue 3 - 2018

\author{
Raúl Fernando Guerrero-Castañeda,' María \\ de Guadalupe Navarro Elías,' Tânia Maria de \\ Oliva Menezes ${ }^{2}$ \\ 'Nursing Professor, Department of Clinical Nursing, University \\ of Guanajuato, México \\ ${ }^{2}$ Associate Professor, Federal University of Bahía, Brazil
}

Correspondence: Raúl Fernando Guerrero-Castañeda, Department of Clinical Nursing, Division of Health Sciences and Engineering, University of Guanajuato. México, Tel 46I-598-5922, Email: ferxtom@hotmail.com

Received: June 04, 2018 | Published: June 20, 2018

\section{Introduction}

In Mexico there is a notable increase in the elderly population, the elderly is that person who is 60 years old and older. In Mexico, for the 2010 year in the INEGI Population and Housing Census, the population over 60 years of age in Mexico now exceeds 10.9 million inhabitants, which represents more than 9.3 percent of the total population. ${ }^{1}$ According to Gerontological Care Models in México, old people's home can be located as shelters. The shelters for older adults, is called the establishment where accommodation services are provided temporarily to older adults, while they are relocated to other institutions or their families, both are governmental institutions, but in Mexico there are residences that provide housing for the elderly, without any regulation. ${ }^{2}$ There is no clarity of functional old people's home at the national or state level, since many of them function by public charity, some are only registered governmentally, but do not have a defined structure. The old people's home in Mexico represent an option that arises from the lack of caregivers at home or lack of availability and time and are places where the elderly face various situations in addition to their aging.

The institutionalized elders have various emotional-type affections that affect their spirituality and their perspective of hope and life; depressive symptoms appear, isolation, loneliness and uncertainty that challenge the perception of well-being. ${ }^{3}$ The elderly have an important spiritual connection, generally the spirituality increases in old age, different resignifications are experienced in relation to life, the person, the universe and the sacred. There is a mystical connection and older adults experience a sense of internal connection with the universe. ${ }^{4}$

Generally the elders seek refuge in spirituality, this one more preserved as religiosity through practices such as prayer and connection with a particular God, even more in institutions such as old people's home it is reflected that spirituality has a remarkable impact on the quality of life of older adults. ${ }^{5}$ The institutionalized elders could keep their spirituality and beliefs, since it is something that is maintained throughout life, this could be a resource for their hope. The institutionalization of the elderly can be a factor that triggers emotional problems that make them lose their hope in life, however, it is characteristic of old age an approach to the spiritual and religious, so the objective was to describe spirituality in a group of elderly Mexican residents of old people's home.

\section{Material and methods}

Quantitative, observational, descriptive and transversal study. It was carried out in a group of elderly residents of seven old people's home in Celaya, Guanajuato, Mexico from July 2017 to January 2018. The population was 79 elderly, a consecutive non-probabilistic sampling was selected $(\mathrm{n}=28)$. Inclusion criteria: To be a resident with more than one month, male or female, be 60 years old; Exclusion criteria: have an inability to verbal communication. The collection of data was carried out using a Sociodemographic Identification Card, for the variable Spirituality the Spiritual Perspective Scale was used with 10 items that evaluate beliefs and spiritual practices ${ }^{6}$ The scale has two dimensions: Spiritual practices (4 items, response from "Not at all" $=1$ to "About once a day" $=6$ ) and Spiritual beliefs (6 items, response from "Strongly"=1 to "Strongly agree"=6). The information was captured in the SPSS Program v.22 and descriptive statistics were done with frequencies and percentages. The study was approved by the Research Committee of the Division of Health Sciences and Engineering of the University of Guanajuato.

\section{Results and discussion}

The average age of the participants was 80.5 years (+/- 8.25), $60.7 \%$ were women, widowhood predominates $(71.4 \%), 85 \%$ profess Catholicism, they have a professional school degree (32.1\%), 96.4\% have a family caregiver, being this caregiver predominantly a son 
(86.4\%), $50.0 \%$ have more than one disability, $39.3 \%$ of these usually use a walker, only $50 \%$ receive a pension. The predominance of the female sex stands out, which reflects that the woman continues to have a high life expectancy, likewise the average age of 80.5 years reflects the increase in this life expectancy. ${ }^{7}$ The Mexican elder is identified more often with Catholicism, which indicates adherence to a religious cult, in Mexico the Catholic religion is predominant. ${ }^{7}$ Religion is present in the life of the elderly, the cultural context makes the elders have a closeness to a religious belief and participate in the cult. Most elderly residents suffer from more than one disease, it is worth mentioning that $50.0 \%$ have more than one disability, $39.3 \%$ of them usually use a walker. In Mexico, a high frequency of elderly people suffers from a disability, the most common being motor disability. ${ }^{7}$ The living and health conditions of the Mexican population reflect the quality of their health, aging is noticeably affected by the declining changes and observes those elderly people who may be dependent. In the evaluation of Spirituality through the Spiritual Perspective Scale, the average was $46.50(+/-9.09)$, the score goes from 10 to 60 , the higher the score, the greater the spiritual perspective, the reliability of Cronbach's Alpha was of .798 for the sample, in the present study there was a high spiritual perspective for the elderly. In Spiritual Practices, $67.9 \%$ of the elderly pray privately at least once a day, talk about spiritual matters with others and share joys and problems related to spirituality they practice at least once a day, $50 \%$ of the elderly never read spiritual readings. In relation to Spiritual beliefs $60.7 \%$ of the elderly believe that beliefs are extremely important, while $39.3 \%$ agree that beliefs respond to a meaning in their life. The spiritual perspective obtained in this study a high average of $46.50(+/-$ 9.09), likewise coinciding with other authors where the spirituality of the elderly is high ${ }^{7,8}$, theoretical studies suggest that as you get older you have stronger connections with spirituality. ${ }^{9}$ Spirituality is part of the subjective human being and is a resource that can have different perceptions, being part of people's lives. Spiritual practices are usually summarized in prayer, an act that provides closeness to God, in this study the elders practice prayer or prayer at least once a day, other authors suggest that faith and prayer to a God generate harmony, inner peace, provides tranquility and helps overcome adversity. ${ }^{10}$ Likewise, the reading of religious texts was highlighted in this study although only $50 \%$ of the elders read something about spirituality, this reflects the practice as something important for them, coinciding with authors on the importance of the pious reading that endows with a sense of self-reflection to the elderly ${ }^{11}$ however, the practice is limited in half of the elderly, the institutionalization can be a limiting factor, as not everyone receives visits and does not have access to religious texts, so it would be imperative that they be provided with texts that they consider valuable for this reflection. A good percentage of the elderly talk about spiritual matters and share with others at least once a day, this reflects that spirituality in multiple variants is a topic of interest in the elderly resident, so that this is shared with others: fellow residents or their families. This reveals that spirituality can favor personal well-being ${ }^{10}$ In relation to beliefs, there was a high score, coinciding with other studies that suggest that beliefs are a fundamental part that gives the human being meaning, especially if the elderly are institutionalized their beliefs and history of religiosity are respected and allows to improve the well-being of residents. ${ }^{3,11}$ In this study the elders report that spiritual beliefs are important, while they are extremely in agreement that beliefs help them, giving them a meaning of their lives. This coincides with multiple studies that speak of the relationship between spirituality and meaning in life, with a strong connection between both, being together protectors of multiple adversities in old age such as institutionalization, depression, among others. Other authors also suggest that it is the beliefs that give meaning and that these can be promoted by the nurse in the homes of the elderly, fostering the meaning of life. ${ }^{10}$ Spirituality can favor the welfare of the institutionalized elderly in the home of the elderly, favoring their sense of life and their personal transcendence, spirituality is an inherent resource of the human being, so that institutionalization cannot be a barrier, for on the contrary, it can be provided in homes for the elderly with spiritual and religious practices that promote personal beliefs and promote well-being, the meaning of life and the search for peace and harmon. ${ }^{12}$

In Mexico, the majority of the old people's home does not have the assistance of health staff; authors in other contexts report that when the nurse establishes an interaction with the residents, the spirituality increases with that relationship, then nursing can consider this concept in the care it provides and can be promoted in the old people's. The limitations of the present study were the sample that turned out to be small, this small sample requires our interest, because of a reasonably larger population, the sample was reduced because the rest of the elders did not have verbal communication capacity, and this reflects the physical, functional and cognitive conditions of the elderly in old people's home. Although the results cannot be generalized, they can be considered for the work of the nurse in old people's home where nursing care is not provided.

\section{Conclusion}

Elderly residents of old people's home in Mexico can face various negative situations added to the deficiencies of aging. The majority of old people's home in Mexico function by public benefit, there are other households that are part of the Government and are public, and others that are private. The elderly residents of old people's home present a high spiritual perspective delimited in this study by the perception of spiritual beliefs and spiritual practice; the practices focus on prayer and reading spiritual texts. The spirituality gives meaning in life of the elderly residents, for this reason it is necessary that the homes have nursing staff, because it is through the spiritual care that tools can be provided that favor the spiritual well-being of the elderly. It is necessary for the nurse to act in old people's home in Mexico, to be introduced in these places to provide care that, besides focusing on physical care, can provide and facilitate spiritual care.

\section{Acknowledgements}

To all the elders who participated and to the Old people's Homes for the support.

\section{Conflict of interest}

The author declares no conflict of interest.

\section{References}

1. Help Age International. Age watch report card México. Global Age Watch Index 2015: Report Card México, Mexico, 2015.

2. Instituto Nacional para las Personas Adultas Mayores. Modelos de atención gerontológica. In: Mayores IN para las PA, editor. México, DF: INAPAM 2002.

3. Mukherjee SB. Spirituality and Religion: Elderly's Perception and Understanding. Indian J Gerontol. 2016;30(3):336-354. 
4. Jewell AJ. Tornstam's notion of gerotranscendence: Re-examining and questioning the theory. J Aging Stud. 2014;30:112-120.

5. Soares ASF, Amorim MISPL. Qualidade de vida e espiritualidade em pessoas idosas institucionalizadas. Rev Port Enferm Saúde Ment. 2015;(SPE2):45-51

6. Reed PG. Spirituality and well-being in terminally ill hospitalized adults. Res Nurs Health. 1987;10(5):335-344.

7. Instituto Nacional para las Personas Adultas Mayores. Perfil sociodemográfico de adultos mayores. México: INEGI; 2014:201.

8. Rocha ACAL, Ciosak SI, Rocha ACAL, et al. Chronic Disease in the Elderly: Spirituality and Coping. Rev da Esc Enferm da USP. 2014;48(2):87-93.
9. Souza ÉN, Oliveira NA, Luchesi BM, et al. Relationship between hope and spirituality of elderly caregivers. Texto Context Enferm. 2017;26(3):1-8.

10. Haugan G, Rannestad T, Hammervold R, et al. The relationships between self-transcendence and spiritual well-being in cognitively intact nursing home patients. Int J Older People Nurs. 2014;9(1):65-78.

11. Reis LA, Menezes TMO. Religiosity and spirituality as resilience strategies among long-living older adults in their daily lives. Rev Bras Enferm. 2017;70(4):761-766

12. Pocinho R, Belo P, Antunes A, et al. Importance of Religiosity and Spirituality in Institutionalized Elderly. ARC J Public Heal Community Med. 2016;1(1):22-30. 